Revista General de Información y Documentación ISSN: 1132-1873

http://dx.doi.org/10.5209/RGID.56564

\title{
El portal de la red de bibliotecas públicas de Castilla-la Mancha. Estudio de caso
}

\author{
Ana María Ventosa Beatty ${ }^{1}$; Alexandre López-Borrull ${ }^{2}$
}

Recibido: 12 diciembre 2016 / Aceptado: 3 de mayo de 2017

Resumen. Desde su creación en 2012, el Portal de la Red de Bibliotecas Públicas de Castilla-La Mancha ha ido sumando secciones y servicios por lo que se considera interesante una evaluación del mismo. Se realiza una evaluación de distintos parámetros, a la vez que una encuesta entre los profesionales de las Bibliotecas para considerar su posicionamiento y utilidad. Algunas de las principales conclusiones son la necesidad de incorporar elementos de atracción, un índice por temas y bibliotecas, una mayor actualización de contenidos y la reorganización de contenidos y la reestructuración del menú principal.

Palabras clave: Portales web; Intranet; Extranet; Redes de bibliotecas; Castilla-La Mancha.

\section{[en] The portal of the public libraries network of Castilla-la Mancha. Case study}

Abstract. Since its launch in 2012, the Portal of the Network of Public Libraries of Castilla-La Mancha has been adding sections and services. An evaluation of the service is considered. Two different methodologies are chosen: Evaluation of different parameters and survey among library professionals to consider their position and usefulness. Some of the key findings are the need to incorporate elements of attraction, a subject index and a libraries index, a major update of content and content reorganization and restructuring of the main menu.

Keywords: Web portals; Extranet; Intranet; Library network; Castilla-La Mancha.

Sumario. 1. Introducción. 2. Metodología. 3. Resultados. 4. Discusión y recomendaciones. 5. Conclusiones y futuras líneas de investigación. 6. Referencias bibliográficas.

Cómo citar: Ventosa Beatty, A. M., López-Borrull, A (2017) El portal de la red de bibliotecas públicas de Castilla-la Mancha. Estudio de caso, en Revista General de Información y Documentación 27 (1), 107-135.

\footnotetext{
1 Biblioteca Municipal de Casas de Juan Núñez (Albacete).

E-mail: casas-juan-nunez@local.jccm.es

2 Universitat Oberta de Catalunya

E-mail: alopezbo@uoc.edu
} 


\section{Introducción}

Se presenta la evaluación del Portal de Bibliotecas Públicas de Castilla-La Mancha (PBPCM, de ahora en adelante) desde dos perspectivas: una de ellas es evaluar si el acceso público a la ciudadanía cumple con los objetivos y filosofía de su creación, y por otro lado, se pretende analizar el uso del portal por parte de los profesionales, así como de los recursos que tenemos a nuestra disposición para el apoyo en el ejercicio de nuestras funciones. Desde su creación en 2012 se han ido añadiendo contenidos, sin embargo, no se había realizado un análisis exhaustivo sobre su impacto. Es por ello que se ha considerado necesaria esta investigación.

Como referencias en la bibliografía encontramos por ejemplo a Vaughman (2001), que estudió la actualización del portal de la Universidad de Nevada creado en 1996, con revisiones importantes en 1998 y 2006. Cada una de ellas ha supuesto una revisión de la página de inicio y debates sobre el diseño del sitio y su contenido. Para la elección de parámetros e indicadores con los que evaluar el portal, Merlo Vega (2003) señala que "la evaluación de la calidad de la información web es especialmente importante para los servicios o instituciones que mantienen directorios de recursos en internet. Se requiere una planificación concreta en la que se establecerán los criterios que se aplicarán y los métodos mediante los que se pondrán en práctica dichos criterios". Por su parte, Ayuso García y Martínez Navarro (2006) proponen un protocolo de actuación para la evaluación de fuentes de información digitales y aportan una guía de buenas prácticas. Asimismo, Lluís Codina (2000) define los parámetros, los indicadores y las preguntas que serán usados en nuestro estudio.

Desde otra aproximación, al estudiar los Portales de Bibliotecas, Figuerola, Alonso Berrocal y Zazo (2013) analizan la cooperación entre las Bibliotecas Nacionales de la Comunidad Europea a través de los enlaces de sus páginas web, así como las relaciones entre los perfiles de las Redes Sociales, determinando que Reino Unido y España son las que más influencia tienen en el conjunto de las Bibliotecas Nacionales. Sellés-Carot y Serrano Cobos (2011), por su parte, indican que "lo que se necesita realmente es una forma de conectar varias familias de software que cumplan por separado su función. Se trata de encontrar una forma de hacerlo convivir y sumar fuerzas (y funciones) en un entorno lo más abierto posible, que permita a las bibliotecas tomar el control de lo que realmente quieren que sea su portal, en función de su política propia y de la naturaleza y necesidades de los usuarios". Así, concluyen que las bibliotecas tienen que ofrecer servicios en sus portales mediante una mayor integración de sitios web de forma que la suma de las partes aporte a los usuarios un valor añadido mucho mayor que el actual, en el que se trabaja por separado.

Castillo Díaz y Jiménez Fernández (2010) van más allá y analizan los mensajes relacionados con la comunicación corporativa de los portales de 17 instituciones del entorno de la biblioteconomía y la documentación seleccionadas del anuario 2009 de la Fundación Alonso Quijano. Para ello, consideran indicadores como la "existencia de mensajes, adaptación de los mensajes al público objetivo, traducción de los mensajes, refuerzo del contenido de los mensajes, etc.". Por su parte, Parker 
(2007) concluye que "lo importante es que los usuarios accedan a los contenidos". La otra vertiente de la investigación se centra, como hemos señalado anteriormente, en la gestión del conocimiento en el PBPCM por parte de los profesionales al frente de las bibliotecas. Sobre ello, Villaseñor y Úcar (2011) describen en su trabajo la generación de capital social partiendo de la postura de los bibliotecarios, ya que "son ellos el vínculo entre la institución y los usuarios". Por su parte, Maniega-Legarda, Pérez-Salmerón y Guerrero-Torres (2008) concluyen que "los profesionales de las bibliotecas públicas han de comunicarse de forma directa, compartir información y trabajar de forma colaborativa a través del portal extranet, traspasando las barreras de la distancia y las dificultades tecnológicas".

Asimismo, Tramullas (2015) realiza una revisión bibliográfica completa y rigurosa del término gestión de contenidos centrándose en el software libre. Por su parte, Calvo-Flores, Cano-Vers y Permanyer-Bastardas (2010) al referirse a los elementos clave del trabajo en red y los valores de la cooperación, "destacan la compartición del conocimiento de los profesionales de la Red y aprovechamiento de sus experiencias generando inteligencia colectiva". En el mismo sentido, concluyen Sarrafzadeh, Martin y Hazeri (2010) que en general, "las bibliotecas han estado involucradas en la gestión del conocimiento a través de la aplicación de sus habilidades en la organización y recuperación de información". Gómez Lendínez y Toboso Vicente (2013) distinguen dentro de un portal de la Red de Bibliotecas Municipales de la provincia de Barcelona, la parte dirigida a los usuarios, el portal técnico y la intranet corporativa, cada una con contenidos diferenciados. Soto y Soescún (2015) realizaron un estudio Delphi en las bibliotecas públicas de Colombia, donde constatan que los expertos están de acuerdo con que "las bibliotecas públicas dejarán de trabajar de manera individual y aislada y requieren generar estrategias de gestión colaborativa y multidisciplinar, así como trabajo en red con instituciones de diversa índole".

Por su parte, en la Universidad de Alabama, Jason (2010), se creó una intranet para centralizar la información interna importante con el fin de facilitar y promover una amplia participación, un calendario para que todos los bibliotecarios sepan lo que está pasando en la universidad y chats como herramienta útil para la comunicación, ya que es más fácil hacer preguntas rápidas que interfieran lo menos posible frente a una llamada telefónica, una visita personal y más rápido que el correo electrónico. Asimismo, en la Universidad de San Diego se migró de una intranet HTML estática a una intranet wiki, destacando que "lo importante es el éxito de una intranet para crear valor para la organización y los empleados como herramienta de comunicación" (Jeffery y Dworak, 2010). DeeAm (2010) por otro lado, trata el aspecto de futuro de las bibliotecas y las amenazas frente a los motores de búsqueda de internet como Google, señalando que "en la Universidad de Nebraska se desarrolló un portal que proporcionará información relevante para distintas poblaciones".

Por tanto, a partir de la bibliografía consultada, tenía pleno sentido evaluar el PBPCM como estudio de caso escogido. 


\section{Metodología}

En el año 2012, la Consejería de Educación, Cultura y Deportes de Castilla-La Mancha se plantea el proceso uniformador de los Servicios bibliotecarios públicos de la región, tomando como punto de partida el catálogo colectivo, ya que se contaba con distintos accesos y páginas web a distintas bibliotecas que ofrecían gran cantidad de información de forma muy dispersa. Así pues, desde el Servicio de Bibliotecas, Libro y Lectura se diseña el Portal de la Red de Bibliotecas Públicas de Castilla-La Mancha como recurso de información dirigido a la ciudadanía ${ }^{3}$. En el mismo artículo se detalla que el diseño del PBPCM "está estructurado en dos partes bien diferenciadas: una, de carácter público, en la que se incluye información de interés general, y otra de carácter restringido, en la que figura sólo aquella de interés para el personal bibliotecario", y es en este aspecto donde se pone énfasis destacando que, desde hace tiempo, ha existido una gran demanda por parte de los profesionales de la Red de Bibliotecas Públicas en disponer de un espacio propio en el que dar cabida a contenido de carácter más técnico: una sección de noticias para personal bibliotecario, un blog, que sirva de canal de comunicación entre diferentes grupos de trabajo, un apartado con documentación técnica, etc.

Para la realización de este estudio se han desarrollado dos metodologías: la primera de ellas, es una evaluación cualitativa, a partir de la propuesta de Codina (2008), que nos permite repasar punto por punto los aspectos a mejorar del portal, centrándonos en los siguientes parámetros e indicadores:

- Parámetro «autoría/fuente»: autoría y comunicación.

- Parámetro «contenido» con siguientes indicadores: tema, público y objetivos, interés intrínseco, oportunidad, política editorial, cantidad, rigor, edición, actualización, recursos multimedia, recursos interactivos, archivo/hemeroteca.

- Parámetro «navegación y recuperación»: navegación constante jerarquización, índices, sistema de etiquetas e iconos, recuperación de la información.

- Parámetro «ergonomía»: facilidad, flexibilidad, legibilidad, recursos multimedia y velocidad.

- Parámetro «luminosidad»: enlaces, contexto de anclaje, anticipación oportunidad, calidad, actualización y tratamiento.

- Parámetro «acceso a la información»: navegación principal, mapa de la web, expresividad, identificación, recorrido secuencial, navegación estructural, orientación, jerarquización, sumarios locales, índices, navegación semántica, sistema de etiquetas, recuperación de la información, búsqueda avanzada, lenguaje documental.

3 "Nuevo portal de la Red de Bibliotecas Públicas de Castilla-La Mancha". En: Anaquel: Boletín de libros, archivos y bibliotecas de Castilla-La Mancha, 2012, n. 53, pp. 5-6 [Disponible en]: file://C:/Users/alopezbo/Downloads/anaquel_53.pdf 
- Parámetro «ubicuidad»: título, transparencia, meta información, Dublin Core, popularidad.

- Parámetro «usabilidad»: visión de estatus, convenciones, errores y anticipación

Por lo que respecta a la accesibilidad, ésta se analizó a través de un análisis con la herramienta HERA (utilidad para la accesibilidad de las páginas web).

En cuanto a la segunda metodología, se centra en el estudio de la gestión y uso del PBPCM por parte de los profesionales de Castilla-La Mancha. Para ello, se elabora una encuesta orientada a conocer el uso que se hace del portal, se envía a través del Servicio de Bibliotecas, Libro y Lectura de la Consejería de Educación, Cultura y Deportes de Castilla-La Mancha a un total de 483 bibliotecas de las cuales se obtuvieron 78 respuestas, lo que supone un $16,14 \%$ de participación. Para comprobar si la muestra es suficientemente representativa, como se detalla a continuación, nos centramos en las respuestas de ámbito numérico para realizar comparaciones objetivas, dividiendo la muestra en estratos de tamaño poblacional de las bibliotecas:

- 2 encuestas de bibliotecas de entre 0 y 500 habitantes $\rightarrow$ GRUPO A

- 12 encuestas de entre 500 y 1000 habitantes $\rightarrow$ GRUPO B

- 40 encuestas de entre 1000 y 5000 habitantes $\rightarrow$ GRUPO C

- 4 encuestas de entre 5000 y 10000 habitantes $\rightarrow$ GRUPO D

- 21 encuestas de más de 10000 habitantes $\rightarrow$ GRUPO E

Respecto a la pregunta realizada en la encuesta sobre si era cómodo y fácil agregar información a la biblioteca, la media aritmética de respuestas ha sido (con puntuaciones de 1 a 5)

Tabla 1. Fuente (elaboración propia)

\begin{tabular}{|l|l|}
\hline GRUPO & MEDIA \\
\hline A & 1 \\
\hline B & 2,8 \\
\hline C & 2,5 \\
\hline D & 3 \\
\hline E & 2,7 \\
\hline
\end{tabular}

A la cuestión sobre si se consultaba el portal para estar informado de los cursos, la media aritmética de respuestas ha sido (con puntuaciones de 1 a 5) 
Tabla 2. Fuente (elaboración propia)

\begin{tabular}{|l|l|}
\hline GRUPO & MEDIA \\
\hline A & 2 \\
\hline B & 2,7 \\
\hline C & 2,8 \\
\hline D & 3,6 \\
\hline E & 3,2 \\
\hline
\end{tabular}

Los encuestados respondieron a continuación sobre si la información profesional de localizaba fácilmente. La media aritmética de respuestas ha sido (con puntuaciones de 1 a 5)

Tabla 3. Fuente (elaboración propia)

\begin{tabular}{|l|l|}
\hline GRUPO & RESPUESTAS \\
\hline A & 2,5 \\
\hline B & 2,3 \\
\hline C & 3 \\
\hline D & 2,6 \\
\hline E & 3,4 \\
\hline
\end{tabular}

Se observa que:

- Las puntuaciones son muy próximas unas de otras, salvo algunos picos producidos por los grupos $\mathrm{A}$ y $\mathrm{D}$, estratos donde la muestra es mucho más pequeña.

- En los grupos más numerosos, hay una homogeneidad en las respuestas.

- Las respuestas de los grupos C y E (los más numerosos), son muy aproximadas.

A partir de los datos obtenidos se realizó un análisis cuantitativo y cualitativo de los resultados que se presentan a continuación.

\section{Resultados}

\subsection{Resultados de la observación}

Lluís Codina (2000) describe la importancia de la evaluación para saber determinar el valor o la capacidad relativa de cumplir sus objetivos de los recursos digitales en línea. Utilizando sus parámetros e indicadores, se procede a realizar el análisis obteniendo los siguientes resultados. Así, para el estudio de los distintos aspectos referentes a los criterios Autoría/Fuente y Contenido, se responden algunas de las preguntas propuestas por Codina (2008) adaptándolas al PBPCM, como puede observarse en la tabla 4. En este sentido, tanto por lo que respecta a la calidad 
como la cantidad de información, nos centramos en la indicación de autoría de la institución que lo ha desarrollado, así como la cobertura de la información contenida en relación a los principios y filosofía de creación.

Tabla 4. Criterios Autoría/Fuente y Contenido. Fuente: Adaptación de Codina (2008)

\section{AUTORÍA/FUENTE}

Autoría: ¿la responsabilidad intelectual del recurso y/o identificación del PBPCM de la publicación están bien localizados?

Comunicación: ¿existe la posibilidad de enviar mensajes al PBPCM?

\section{CONTENIDO}

Tema, público y objetivos: ¿está explicado, o al menos puede deducirse con facilidad el tema, los objetivos y el público de la web del PBPCM?

Interés intrínseco: ¿el tema de la publicación es intrínsecamente adecuado o valioso para el mundo de la educación, la investigación, la cultura o la I+D+I?

Originalidad/Oportunidad: ¿proporciona información de un tema del que existe, en general, poca información en otros sitios, o bien hay algún aspecto en su forma de presentación, su punto de vista, idioma, calidad, exhaustividad, etc., que no suele encontrarse en otras publicaciones?

Política Editorial: ¿existe una política de revisión?

Cantidad: ¿contiene la web del PBPCM un volumen adecuado o suficiente de información en relación al tema, objetivos y público a los que se supone se dirige el recurso?

Rigor: ¿contiene evidencias o indicios de que la información ha tenido un tratamiento adecuado a la naturaleza y objetivos del PBPCM?

Edición: ¿contiene evidencias o indicios de tratarse de información que ha sido editada por parte del PBPCM?

Actualización: ¿la información ha sido actualizada con la frecuencia adecuada a la naturaleza del recurso?

Recursos multimedia: ¿presenta otra morfología de la información además del texto?

Recursos interactivos: ¿presenta el sitio alguna sección con algún tipo de interactividad aparte de la actividad elemental de hacer clic en los enlaces?

Archivo/hemeroteca: si la publicación ha editado números o volúmenes ¿se ha dispuesto la posibilidad de su acceso o consulta? 
Examinado el parámetro Autoría/Fuente, se constata que responde adecuadamente a las preguntas formuladas. Por lo que respecta al parámetro Contenido, para evaluar el indicador originalidad u oportunidad, se compara con los contenidos de portales de otras redes de bibliotecas. Básicamente, todos comparten las mismas secciones y servicios, pero en el PBPCM se ha incluido la "Agenda Cultural de toda Castilla-La Mancha", lo que es una ventaja para la ciudadanía, ya que desde allí puede consultar este tipo información evitando el laberinto que a veces ocasiona buscarla en sitios dispersos de internet. En este sentido, también se ha incluido la sección "valorar-compartir" que anima al usuario a participar. Asimismo, se ofrece la sección de "los más prestados de la Red" que puede orientar al usuario a nuevas lecturas. Sin embargo, este servicio debería actualizarse con más asiduidad ya que consultando al Servicio de Bibliotecas, Libro y la Lectura, ésta se hace anualmente, corriendo el riesgo que las recomendaciones restulten un poco obsoletas considerando la inmediatez que la moda y las tendencias influyen sobre las lecturas.

Respecto a los indicadores "cantidad" y "actualización", no responden adecuada $\mathrm{y}$ totalmente a las cuestiones formuladas y se observa gran cantidad de secciones e iconos que repiten información. En cuanto a la actualización de la sección "Actualidad literaria" no consta fecha de publicación de las noticias. Ocurre lo mismo con "Los más prestados de la red" con lo cual la ciudadanía no podría dilucidar a qué periodo se refiere. Para el indicador "política editorial" los profesionales disponemos de manuales técnicos de publicación en el portal según permisos, diferenciando entre bibliotecas municipales y resto de bibliotecas, asegurando así que la información es revisada. En cuanto al indicador "Edición" las publicaciones son editadas y evaluadas previamente solicitando permiso de publicación.

Por otra parte, no se abusa de "Recursos multimedia" salvo en las ocasiones que así lo requieren como es el caso del funcionamiento de eBiblio (ver fig. 1).
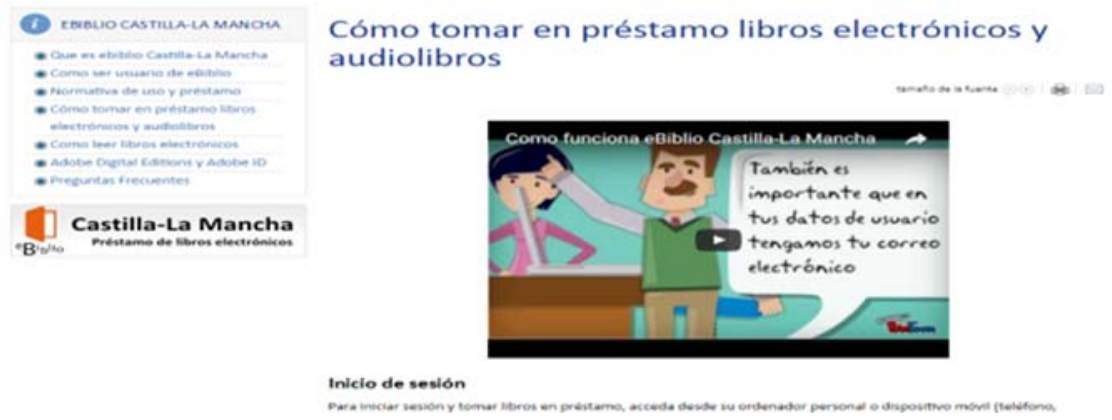

Figura 1. Recursos multimedia. Fuente (elaboración propia)

Aunque el PBPCM no es un portal o web de publicaciones periódicas, el indicador "Archivo" está correctamente empleado en la publicación periódica "Boletín Anaquel" editada por la propia Consejería de Educación, Cultura y 
Deportes de Castilla-La Mancha. Por lo que respecta al criterio "acceso a la información", se evalúan los parámetros "navegación/recuperación" y "ergonomía", consistentes en averiguar si el PBPCM ofrece a los usuarios facilidad en el manejo, y si existe un sistema de recuperación de la información complementario al sistema de navegación a través de la búsqueda por palabras, facilitando además la lectura a través de una buena relación entre figura y fondo con textos que faciliten la lectura. En la Tabla 5 se pueden observar las preguntas y criterios considerados.

Tabla 5. Criterios Navegación y recuperación. Fuente: Adaptación de Codina (2008)

\section{NAVEGACIÓN Y RECUPERACIÓN}

Navegación principal/Sumario: ¿Dispone el PBPCM de una navegación principal claramente diferenciada que presente una visión/sumario de los contenidos o secciones principales del sitio?

Expresividad: ¿La lista de opciones de la navegación principal (sumario) contiene un número limitado de opciones o de conjuntos de opciones bien agrupadas de manera que pueden tenerse a la vista sin necesidad de efectuar desplazamientos con el cursor? ¿Con o sin desplazamiento, el número total de opciones del sumario principal se mantiene en torno a unas pocas unidades, caso ideal, o unas pocas decenas o bien se acerca e incluso supera el medio centenar, caso peor?

Identificación: ¿Contiene cada página o sección del PBPCM un título, un autor (si procede) y una fecha de actualización (si procede)?

Recorrido secuencial: ¿es posible seguir la estructura de contenidos de forma secuencial?

Navegación estructural: ¿Es posible acceder directamente a cualquier sección importante del PBPCM sin necesidad de pasar por las secciones previas? ¿La estructura de secciones de la publicación es clara y está adecuadamente soportada en la navegación? ¿Se puede acceder a cualquier lugar de la web desde cualquier otro lugar, mediante un pequeño número de elecciones, o lo que es lo mismo, mediante un número de clics relativamente pequeño (5 clics o menos)?.

Orientación: ¿Proporciona orientaciones de contexto que responda a preguntas del estilo ¿dónde estoy?, ¿estoy al principio, en medio o final de algo de qué extensión ?

Jerarquización: ¿Existen evidencias de que los contenidos de la web del PBPCM han sido jerarquizados de acuerdo a su importancia relativa?

Sumarios locales: ¿Contienen las secciones de la publicación menús o sumarios locales que nos ayuden a conocer con detalle su contenido temático y acceder a cualquiera de sus partes con un número mínimo de clics? 
Índices: ¿Contiene índices temáticos, cronológicos, geográficos u onomásticos?

Navegación semántica: ¿existen enlaces que sirven para relacionar secciones o ítems que mantienen entre ellos alguna clase de asociación?

Sistema de etiquetas: Las etiquetas textuales, o los iconos, en su caso, de las opciones de menú, ¿son informativos o son ambiguos? ¿son auto excluyentes o se solapan entre ellos? ¿es consistente el sistema de etiquetas o se designan las mismas cosas con distintos nombres o bien se utilizan diversas convenciones para las mismas funciones?

Recuperación de la información: ¿Posee un sistema de acceso a la información mediante búsqueda por palabras?

Búsqueda avanzada: ¿Permite algún tipo de búsqueda avanzada mediante búsqueda por campos, operadores booleanos, etc...?

Lenguaje documental: ¿Contiene un sistema de búsqueda basada en alguna forma de lenguaje o de tratamiento documental: sistema de clasificación, ontología, descriptores, tesauro...?

El PBPCM ofrece sumario de contenidos, que presenta un número limitado de opciones. Este mismo sumario también se encuentra en la parte derecha, pero requiere de desplazamientos para su completa visualización y su número elevado de opciones hace que al usuario quizás se le sobrecargue de información. Las secciones se "identifican" con título y autoría, adecuadamente (fig. 2).

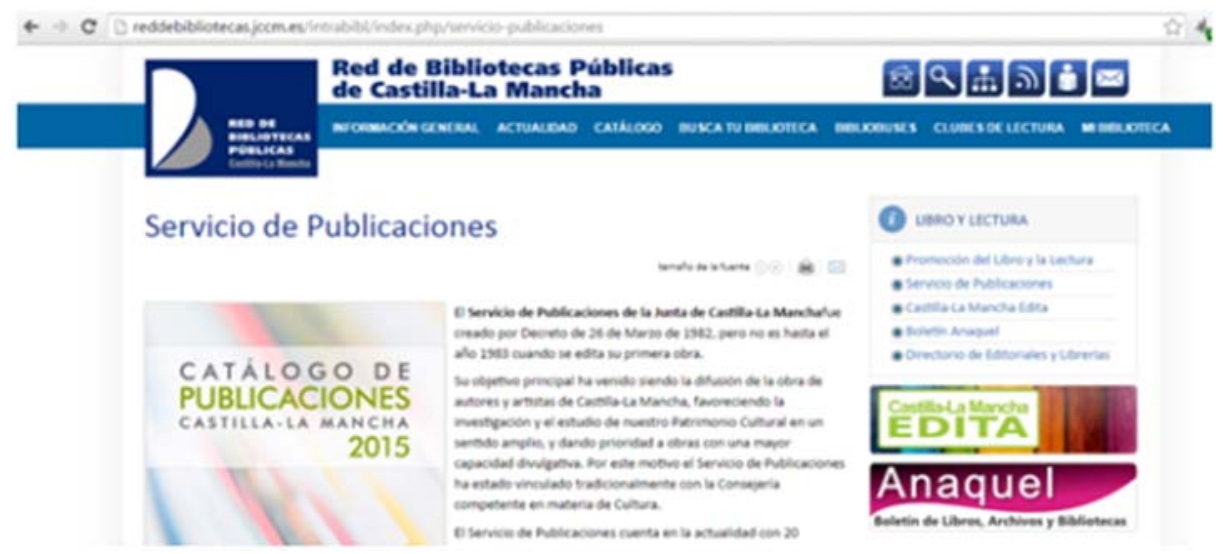

Figura 2. Identificación de secciones. Fuente (elaboración propia) 


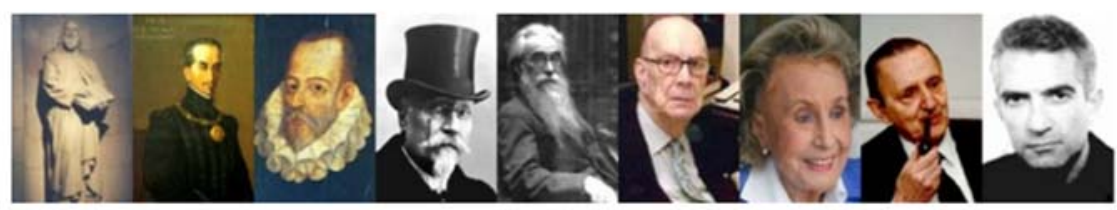

La página web de la Subdirección General de Promoción del Libro, la Lectura y las Letras Españolas, dependiente del Ministerio de Educación, Cultura y Deportes, presenta un nuevo recurso preparar exposiciones bibliográficas, guias de lectura, etc.

En esta sección se encuentra una recopilación de autores españoles cuyos centenarios de nacimiento o muerte se conmemoran en 2016, asi como de aquellos fallecidos hace ahora cincuenta años. Algunos nombres son bien conocidos, pero también se quiere recordar a otros escritores, ahora menos leidos, que asimismo contribuyeron a formar el acervo literario en las distintas lenguas de nuestro pais. De todos ellos se ofrecen datos biobliográficos.

Podéis acceder a la sección Centenarios y aniversarios de autores españoles en este enlace.

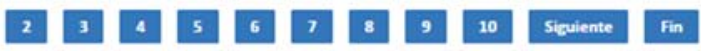

Figura 3. Recorrido secuencial guiado. Fuente (elaboración propia)

El "recorrido secuencial" (fig.3) orienta al usuario sobre dónde ir a continuación, en las secciones que así lo requieren, contenidos extensos, actividades culturales, etc. Asimismo, existe la posibilidad de un recorrido secuencial guiado. Por otra parte, con un máximo de tres clics, se pueden realizar "recorridos no secuenciales" de una sección a otra, con la posibilidad en cada una de las secciones de ir a la página principal, y se observa que algunos enlaces abren pestaña nueva, con lo cual nunca se pierde la página principal evitando así que el usuario abandone la página. En lo referente a la "orientación", ésta viene indicada en las secciones que por su tamaño lo necesitan, sin embargo, no hay constancia de trazas de navegación en todas ellas, ejemplo de ello es, acceder al menú "noticias de interés" sin ofrecer rastro de "¿dónde estamos?" de forma clara, habrá que consultarlo en la barra del navegador: 
(i) reddebibliotecas.jccm.es/intrabibl/index.php/actualidad/noticias/item/4922-xi-jornada-tecnica-para-bibliotecarios-albacete

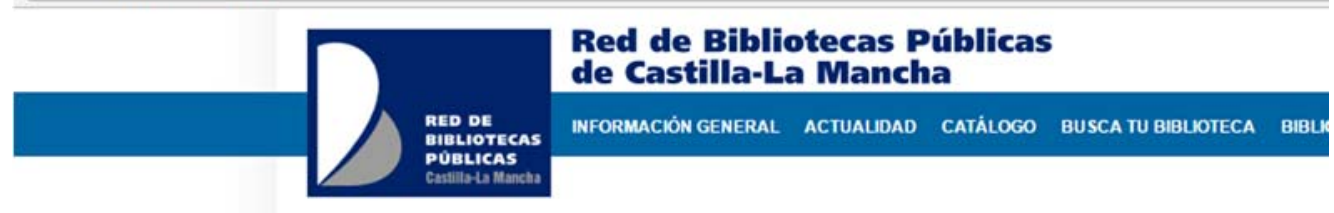

\section{Jornada técnica para bibliotecarios en Albacete}

amakio de la fuente $\odot \odot$ )

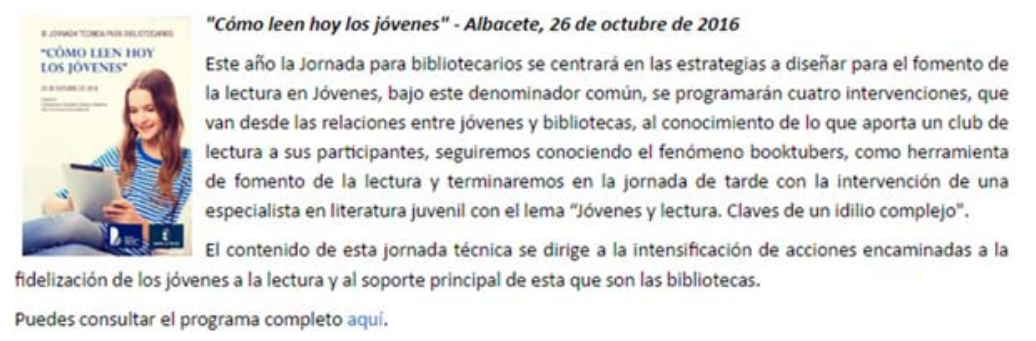

Visto 65 veces

\begin{tabular}{lll}
\hline Twillear & Me gusta \\
Registrarte para ver que les gusta a & G*1 \\
\hline
\end{tabular}

Figura 4. Orientación. Fuente (elaboración propia)

En la figura 5 se observa la sección de "Bibliobuses, donde se puede apreciar que dicha sección sigue un orden lógico de prioridades en la cual la "jerarquización" ha sido adoptada en este recurso.

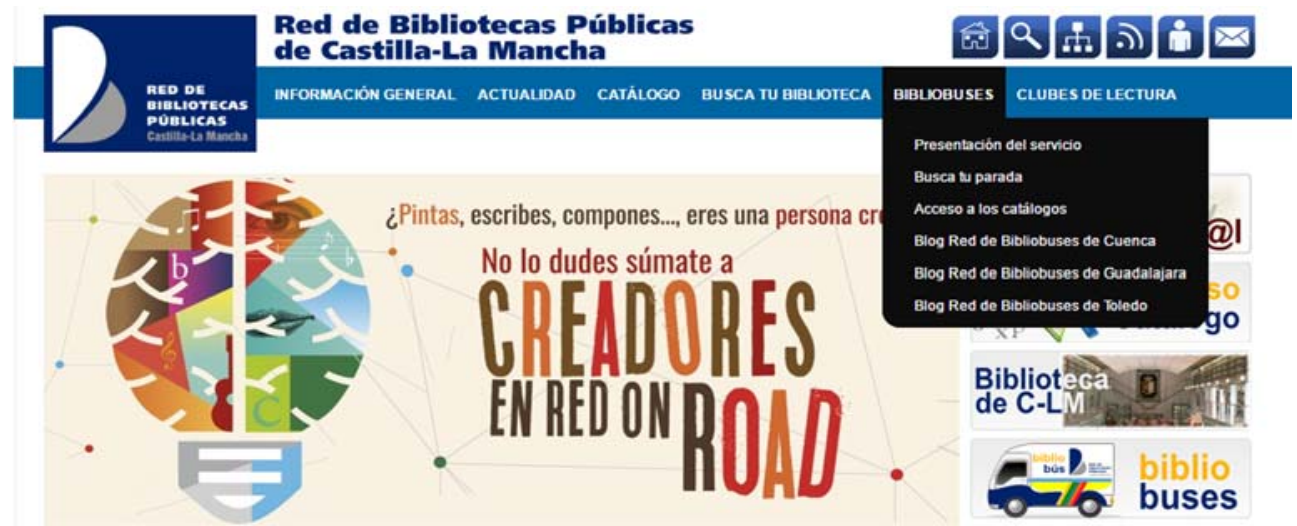

Figura 5. Jerarquización. Fuente (elaboración propia) 
Siguiendo el análisis, se puede observar que El PBPCM dispone de sumario de contenido, pero por la cantidad de los mismos, se proporciona un "sumario local" de las diferentes secciones que así lo precisan. Como se recoge en la bibliografía, el sumario general, no debería incluir detalles de sumarios locales ya que genera desorientación, rompiendo la regla de la jerarquización más abstracción (Codina, 2008).

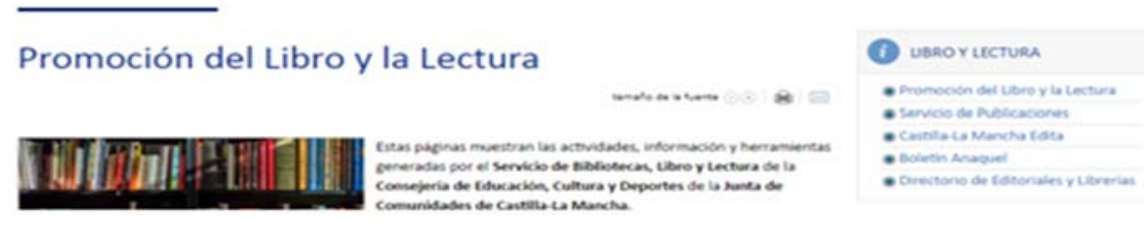

Figura 6. Sumarios locales. Fuente (elaboración propia)

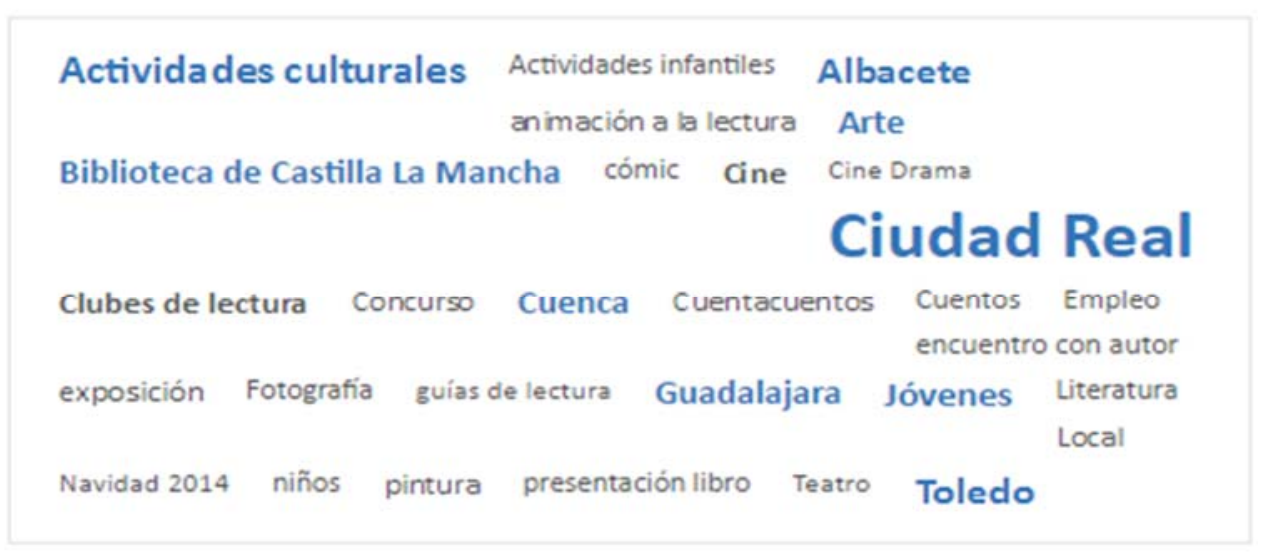

Figura 7. "Nube de etiquetas". Fuente (elaboración propia)

Respecto a la "navegación semántica", nos encontramos con enlaces entre secciones relacionadas aunque no estén indicadas con "temas relacionados, artículos de interés, etc.". Asimismo, el "sistema de etiquetas" se solapa en algunos casos y nos encontramos con secciones que contienen la misma información: "Actividades culturales" contiene la misma información que "Novedades" y dos secciones denominadas "Noticias profesionales" y "Actualidad profesional" albergan ambas el mismo contenido, como se puede observar en las figuras 8 y 9 : 
VIII Congreso Nacional de Bibliotecas Públicas

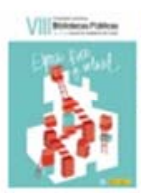

La Dirección General de Bellas Artes y Bienes Culturales $y$ de Archivos y Bibliotecas del Ministerio de Educación, Cultura y Deporte, a través de la...

Makerspaces y bibliotecas - Reseña de Julio Alonso Arévalo para IWETEL.

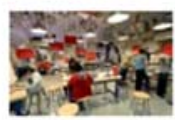

Dado que la información se está convirtiendo cada vez más en un recurso de más fácil acceso a través de redes en linea, las bibliotecas...

\section{Guía de servicios bibliotecarios para} personas con dislexia de la IFLA

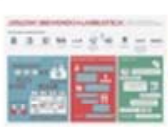

La IFLA ha publicado en su web la traducción de la $2^{\text {a }}$ edición ampliada y revisada de la guía de servicios bibliotecarios para personas con...

Recopilación de centenarios de autores españoles

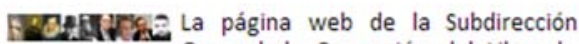
General de Promoción del Libro, la Lectura y las Letras Españolas, dependiente del Ministerio de Educación, Cultura y Deportes,...

Figura 8a. Sistema de etiquetas. Fuente (elaboración propia)

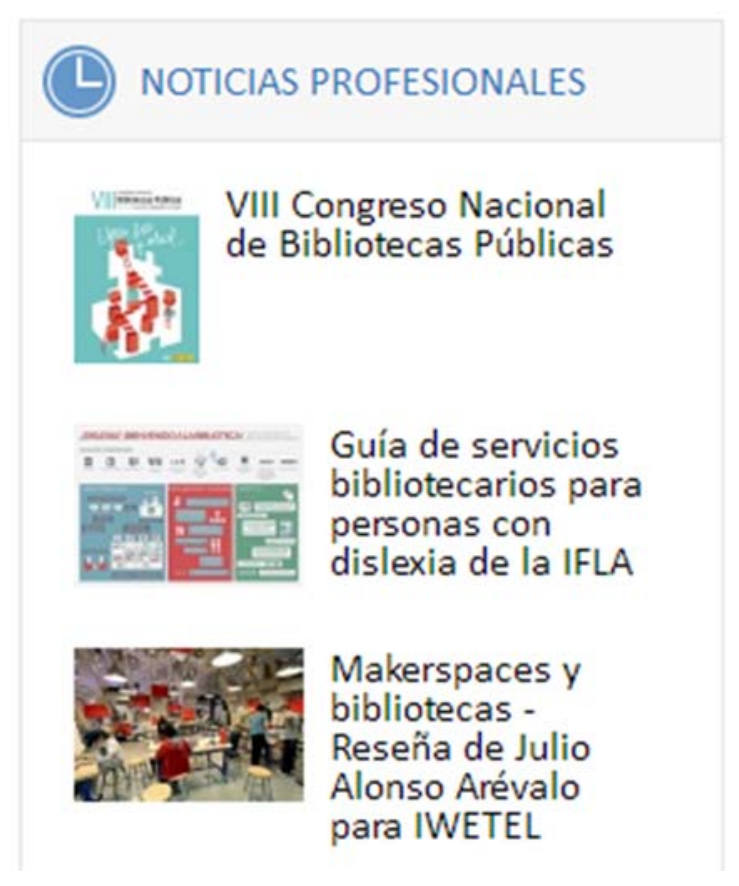

Figura 8b. Sistema de etiquetas. Fuente (elaboración propia) 


\section{Festival literario Almoradiel lee}

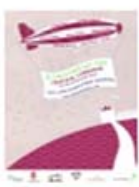

La primera edición del Festival Literario Nacional Almoradiel Lee se celebrará del 2 al 4 de noviembre de 2016 en La Puebla de Almoradiel (Toledo). Festival...

Publicado el 14-10-2016
Iniciación a Internet, Google y correo electrónico. Biblioteca Pública del Estado en Albacete.

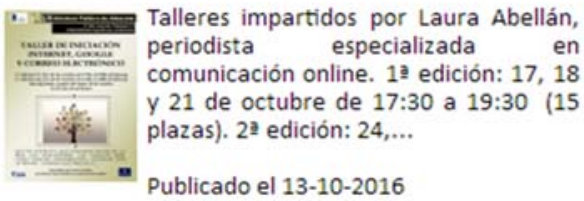

Figura 9a. Sistema de etiquetas. Fuente (elaboración propia)

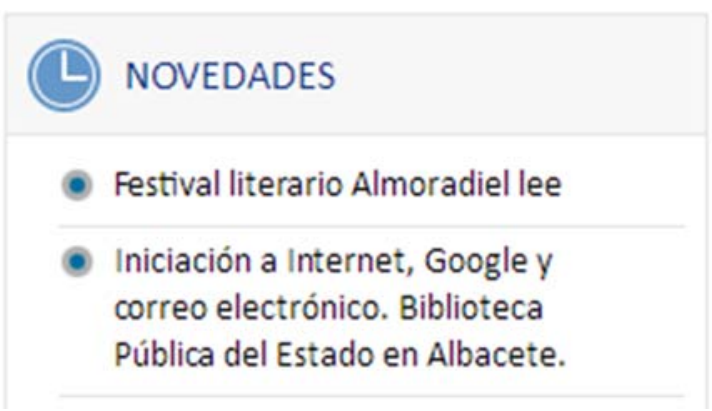

Figura 9b. Sistema de etiquetas. Fuente (elaboración propia)

Bajo el criterio "ergonomía" (ver Tabla 6) se estudia la comodidad y facilidad de utilizar el portal por parte de los usuarios. La tecnología, el diseño y el uso de recursos multimedia han de ser intuitivos, ligeros, cómodos y fáciles de usar por su carácter generalista en cuanto a usuarios potenciales.

Tabla 6. Criterio Ergonomía. Fuente: Adaptación de Codina (2008)

\section{ERGONOMÍA}

Facilidad: ¿Las acciones aparentemente más frecuentes son las más accesibles o, por el contrario, requieren de diversas acciones, desplazamientos, numerosos clics, etc.?

Flexibilidad: ¿Se pueden realizar las mismas acciones de distintas formas?

Claridad: ¿Hay una buena relación figura/fondo en la web del PBPCM, es decir, hay un contraste adecuado entre texto y fondo, entre ilustraciones y texto, entre ilustraciones y fondo? 
Legibilidad: ¿La tipografía empleada: familia de letra y tamaño para los textos es adecuada para una buena legibilidad? ¿Las líneas de texto ocupan toda la anchura de la pantalla y hay pocos espacios blancos, lo cual provoca mala legibilidad y fatiga visual o, por el contrario el texto deja márgenes amplios a los lados y hay espacios en blanco entre los párrafos de texto?

Recursos multimedia: ¿Las imágenes o los sonidos, si las hay, complementan la información textual y son necesarias para la exposición del tema tratado o entorpecen la lectura del texto o, al revés, el texto entorpece la lectura de las imágenes y del sonido?

Velocidad: ¿La velocidad de descarga de las páginas es suficiente, o bien la tecnología utilizada, el tamaño de las imágenes, etc., hacen difícil y lenta la descarga de las páginas teniendo en cuenta los objetivos del recurso y el público destinatario?

Para evaluar la "facilidad" se ha accedido al OPAC del PBPCM por ser probablemente el recurso más utilizado y el punto de partida de la colaboración interbibliotecaria. Se observa que con un total de tres clics se accede al catálogo de cualquier biblioteca. Se observa también que desde cualquier sección del portal se accede con facilidad a la página principal. En cuanto a la "legibilidad", ésta se podría mejorar porque aunque el tamaño de la letra es adecuado, en algunas secciones del recurso se indica que se puede ampliar, aunque se ha comprobado que esta opción no es ejecutable.

Respecto a la visibilidad, se ha estudiado el encaje de la publicación digital en el contexto de internet como un elemento esencial. Bajo este criterio se evalúan la "luminosidad" y la "ubicuidad", refiriéndose la primera al número de enlaces que parten del portal hacia otras sedes web, mientras que la ubicuidad se refiere a la facilidad que presenta el portal para ser localizado. Una buena observación en esta evaluación confirma la facilidad de búsqueda de la web en internet por parte de los usuarios y la utilidad que pueden sacar del portal.

Tabla 7. Criterio Luminosidad. Fuente: Adaptación de Codina (2008)

\begin{tabular}{|l|}
\hline LUMINOSIDAD \\
\hline Enlaces: ¿Posee el PBPCM enlaces a sitios o recursos externos? \\
\hline $\begin{array}{l}\text { Contexto de anclaje: ¿aparecen los enlaces a fuentes externas en el contexto oportuno y } \\
\text { favorecen así el aprovechamiento del material? }\end{array}$ \\
\hline $\begin{array}{l}\text { Anticipación: Si el PBPCM utiliza enlaces incrustados en el contenido de la publicación, } \\
\text { ¿están identificados de manera adecuada de forma que anticipen al lector el resultado de } \\
\text { activar el enlace y, en todo caso, es evidente para el lector que si activa el enlace } \\
\text { abandona el artículo o sección que está leyendo de la publicación? }\end{array}$
\end{tabular}


Oportunidad: ¿El número y la naturaleza de los enlaces es adecuado a las características del recurso o, por el contrario es escaso, excesivo o injustificado?

Calidad: ¿Presenta indicios de que los enlaces han sido seleccionados y evaluados siguiendo algún criterio claro de calidad intrínseca de los recursos enlazados?

Actualización: ¿Están actualizados los enlaces del recurso considerado o, por el contrario, hay abundancia relativa de enlaces obsoletos o "rotos"?

Del análisis del parámetro, se destaca que la "anticipación" ofrecida por el anclaje en el portal redunda, ofreciendo el título de la sección en vez de ofrecer la información sobre dónde nos dirige, queda así demasiado a la intuición del usuario. Al observar la "calidad" de los enlaces, se ve que han sido seleccionados cuidadosamente, no abusando de ellos. Sin embargo, se podrían agrupar por categorías dejando la página principal más despejada.

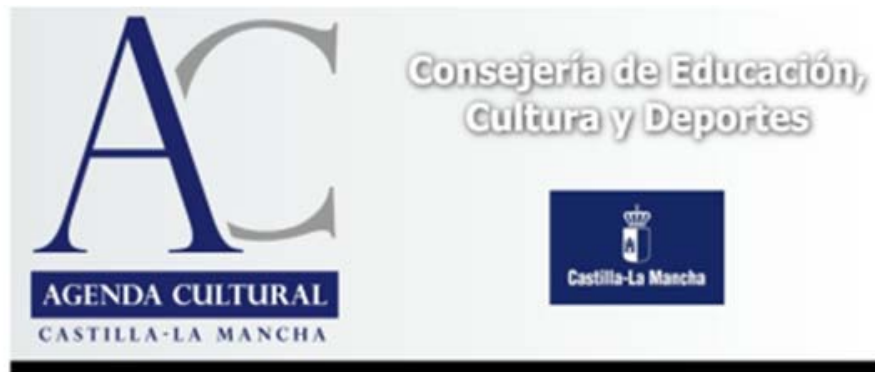

Agenda Cultural de Castilla-La Mancha

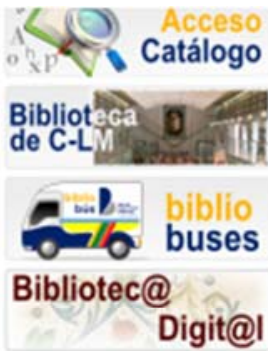

Digit@।

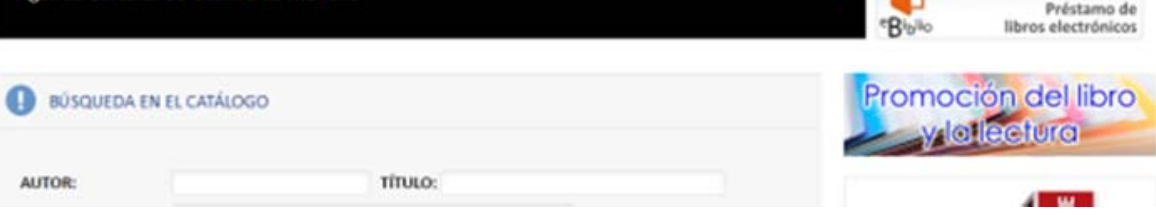

Figura 10. Calidad de enlaces. Fuente (elaboración propia)

La ubicuidad es uno de los componentes del posicionamiento web, correspondiendo a la facilidad del Portal para ser localizado:

Tabla 8. Criterio: Ubicuidad. Fuente: Adaptación de Codina (2008)

\section{UBICUIDAD}

Título: ¿El título del PBPCM que aparece en la barra del navegador de color azul superior es informativo? ¿Tiene título? ¿El título es adecuado, es informativo? ¿Tienen un título propio las diferentes secciones? 
Transparencia: ¿Los primeros párrafos o elementos del PBPCM contienen información en formato textual donde se haga explícito el contenido del recurso o existen otras indicaciones que informan claramente sobre el contenido o el propósito de la publicación?

Meta información: ¿El elemento HEAD de la web contiene al menos algunas etiquetas de metadatos básicas como <author $>$, <keywords $>$ y $<$ description $>$ ? ¿Las etiquetas de los enlaces tienen de forma sistemática el atributo $<$ title $>$ y los enlaces a imágenes tienen el atributo $<$ alt $>$ ?

Dublin Core: ¿El elemento HEAD contiene el sistema avanzado de meta datos Dublin Core?

Popularidad: ¿Es un sitio muy enlazado? Es decir: ¿hay otros sitios o páginas web que contengan enlaces al recurso considerado y, en todo caso, cuántas son?

Se han observado los indicadores "título" y se verifica que en las etiquetas de la sección HEAD del recurso, contiene la etiqueta $<$ Title $>$ con el título del recurso:

\section{〈neta namez" "generator" contentz" Joomla! · Open Source Content llanagement" /> \\ 〈title)Inicio Red de Biblitotecas Castilla -La Mancha</title >

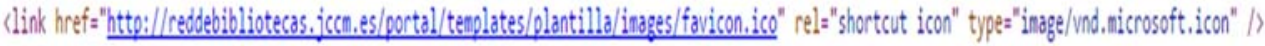 〈link relz"stylesheet" hrefz"/portal/redia/systen/css/modal.css" typez"text/css" /}

Figura 11. Etiqueta $<$ Title $>$. Fuente (elaboración propia)

En la consideración de si el contenido es adecuado o informativo, se observa que es totalmente informativo ya que contiene las palabras "red", "bibliotecas" y la extensión "jccm" que alude a la Junta de Comunidades de Castilla-La Mancha. En lo que respecta al título, cada sección contiene el suyo (fig. 12). Por otra parte, como se puede observar en la figura 12, en la barra del navegador también se muestra el título del PBPCM, con lo que queda suficientemente identificado y significativo. Será indizada adecuadamente, pues, por los motores de búsqueda.

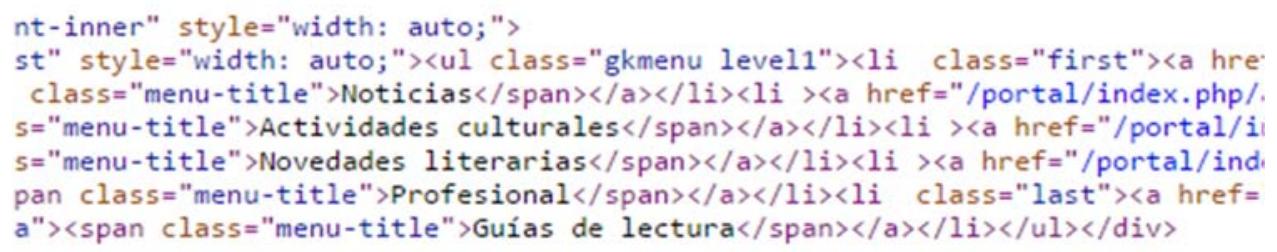

Figura 12. Título de secciones. Fuente (elaboración propia) 


\section{Inicio Red de Biblitotecas C... $\mathbf{\nabla})+$}

\section{(4) (i) reddebibliotecas.jccm.es/portal/}

Figura 13. Título del portal. Fuente (elaboración propia)

Asimismo, se ha podido comprobar que el elemento HEAD del Portal contiene las etiquetas $<$ Keyword $>$ y $<$ Description $>$ aunque no se ha localizado la etiqueta $<$ author $>$.

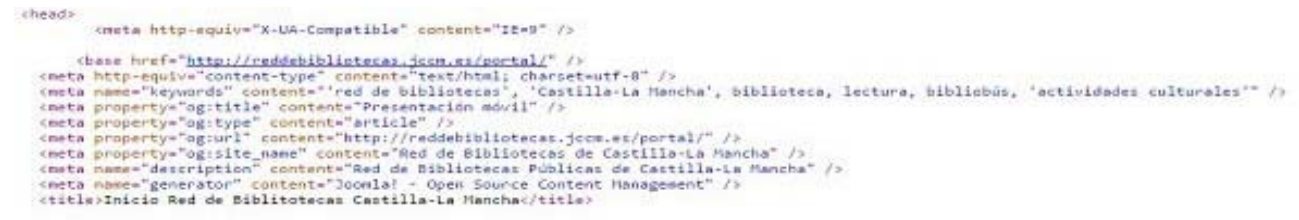

Figura 14. Meta información. Fuente (elaboración propia)

Por lo que respecta a las etiquetas, también se encuentran en la sección "bibliobuses", "promoción del libro", "novedades", "documentación técnica", etc. Si se despliega el código fuente se observa que no se utiliza la norma internacional "Dublin Core". Finalmente, el último indicador de éste parámetro es la "popularidad", correspondiendo al número de enlaces o citaciones que recibe el recurso. Se han obtenido 4640 citaciones, para comprobar la popularidad se realizado el mismo procedimiento con el portal de las Bibliotecas de Castilla y León con un resultado de 5200 citas.

Tabla 9. Criterio Procesos. Fuente: Adaptación de Codina (2008)

\section{PROCESOS}

Visión de estatus: ¿Existen indicaciones del estado de la acción o de la transacción que se está realizando?

Convenciones: ¿Utiliza el PBPCM un lenguaje y un rotulado de iconos transparente y en lenguaje natural y sigue las convenciones más habituales en el manejo de las acciones o transacciones en cada caso o es poco comprensible para usuarios no habituales?

En lo relativo a la "visión de estatus", no es ambigua en el proceso, de forma que cuando el usuario rellena un formulario, si falta algún campo lo indica el sistema, se valida el proceso a través de introducción de caracteres y se da mensaje 
al usuario de "mensaje enviado" o "solicitud procesada". En cuanto al indicador "convenciones", el portal utiliza un lenguaje claro que evita tecnicismos innecesarios.

Tabla 10. Criterio Errores. Fuente: Adaptación de Codina (2008)

\section{ERRORES}

Deshacer acciones: ¿En determinados puntos de la transacción o acción es posible deshacer ésta de manera fácil?

Mensajes: En caso de error, ¿el mensaje del sistema es inteligible o utiliza un argot incomprensible?

Consecuencias: En caso de error del usuario, ¿se ha procurado minimizar las consecuencias?

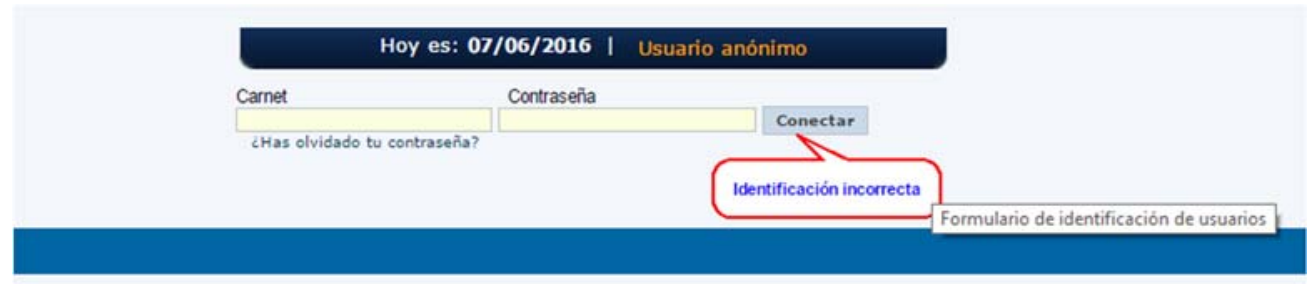

\section{Catálogo General}

Figura 15. Errores y mensajes. Fuente (elaboración propia)

El indicador "errores" del portal ofrece mensajes sin ninguna "consecuencia" ya que se pueden deshacer como se ve en la figura 15.

Tabla 11. Criterio Adaptación. Fuente: Adaptación de Codina (2008)

\section{ADAPTACIÓN}

Adaptación: ¿Pueden los usuarios del PBPCM adaptarlo a sus necesidades, lengua, contexto o intereses personales?

Redundancia: ¿Se pueden realizar las acciones más habituales de distintas formas o se puede acceder a las principales secciones por diversas vías?

Acceso: ¿Las acciones más habituales están presentes en la primera sección del PBPCM y sin necesidad de realizar scrolls o, por el contrario, requieren de diversos clics? 
Política: ¿Hay una sección dedicada a exponer las normas y la política de la institución editora, por ejemplo, respecto a la forma de suscripción, si es el caso, normas de uso, envío de rectificaciones, etc.?

El último indicador analizado es la "adaptación". Se constata que no existe posibilidad de personalizar la página a las necesidades o gustos de los usuarios, mientras que se verifica, como se expuso anteriormente, la "redundancia", la posibilidad de realizar las mismas acciones por diferentes medios. En cuanto al "acceso", éste es fácil, por cuanto el portal consta de un menú principal situado en la parte superior, a través del cual se puede acceder a las secciones con las que originariamente contaba el portal. Cabe recordar que posteriormente se han ido añadiendo recursos los cuales no están en este menú. En cuanto a "política", en el portal se expone la política de carnets de usuarios y normas de préstamo.

En lo relativo al criterio accesibilidad se ha analizado con HERA (utilidad para la accesibilidad de las páginas web), con un resultado de 6 errores de prioridad 2 y 3 errores de prioridad 3, no señalando errores graves. Algunos de los errores destacados son la utilización de medidas relativas para ampliación/reducción de tamaño de letra y la asociación de etiquetas a formularios.

Finalmente, los resultados obtenidos del análisis cualitativo se resumen en la Tabla 12.

Tabla 12. Resumen de los resultados. Fuente (elaboración propia)

\begin{tabular}{|c|c|}
\hline PARÁMETRO & OBSERVACIONES \\
\hline Autoría/Contenido & $\begin{array}{l}\text { Responde adecuadamente a contenidos } \\
\text { Los indicadores "cantidad" y "actualización" no responden } \\
\text { adecuadamente a la preguntas consideradas en el estudio } \\
\text { Correcto uso de "política editorial", "Edición", "Recursos } \\
\text { Multimedia", "Archivo" }\end{array}$ \\
\hline $\begin{array}{l}\text { Navegación y } \\
\text { Recuperación/Ergon } \\
\text { omía }\end{array}$ & $\begin{array}{l}\text { Correcto uso de "identificación", "recorrido secuencial", "recorrido no } \\
\text { secuencial", "jerarquización", "facilidad" } \\
\text { No responden adecuadamente a las preguntas consideradas en el } \\
\text { estudio relativas los indicadores "orientación", "sumario local", } \\
\text { "sistema de etiquetas", "navegación semántica", "índices" y } \\
\text { "legibilidad" }\end{array}$ \\
\hline $\begin{array}{l}\text { Luminosidad/Ubicu } \\
\text { idad }\end{array}$ & $\begin{array}{l}\text { Correcto uso de "calidad", "título", "meta información" y } \\
\text { "popularidad" } \\
\text { No responde adecuadamente a las preguntas respecto los indicadores } \\
\text { "anticipación" y "código fuente" }\end{array}$ \\
\hline $\begin{array}{l}\text { Procesos/Errores/A } \\
\text { daptación }\end{array}$ & $\begin{array}{l}\text { Uso correcto de los parámetros procesos y errores } \\
\text { El indicador "adaptación" no responde adecuadamente a las preguntas } \\
\text { consideradas }\end{array}$ \\
\hline
\end{tabular}




\subsection{Resultados de la encuesta}

La encuesta utilizada para la evaluación del uso del PBCM por parte de los profesionales se envió a través del correo oficial del Servicio de Lectura, Libro, y Bibliotecas con la finalidad de aumentar la difusión. Se consideró que un canal oficial sería el mejor paso. Así, de las 483 bibliotecas que forman el sistema han participado el $16,14 \%$. La participación no ha sido lo elevada que se esperaba, aunque el número de respuestas hace que los resultados se puedan considerar válidos. La encuesta se encuentra dividida en dos apartados, "aspectos del portal" y "el portal y tus usuarios" para obtener información sobre el tipo de biblioteca en que trabajan, la consideración que tienen sobre el portal y la promoción que hacen del mismo entre sus usuarios. En este artículo nos centraremos en los aspectos del portal y de los usuarios.

\subsubsection{Aspectos del portal}

Este apartado de la encuesta establece la relación de los bibliotecarios con el portal, entendiéndolo como una herramienta de trabajo. Con un buen conocimiento de sus servicios y secciones, los profesionales tendrán a mano un buen recurso de información sobre el Sistema de Bibliotecas de Castilla-La Mancha. El 66,2\% de las respuestas muestra que consultan a menudo información de otras bibliotecas, el $66,2 \%$ la consultan a menudo. Otros compañeros lo consultan cuando les llama la atención ciertas actividades culturales, cuando se acercan fechas importantes como la celebración del Día del Libro, por ejemplo. Sobre la afirmación de la facilidad y comodidad de agregar información sobre la biblioteca (valorando del 1, totalmente en desacuerdo a 5, totalmente de acuerdo), en el gráfico 1 se constata que la mayoría de los profesionales ven esta acción muy dificultosa, trabajar en entornos amigables hace que la información fluya y se actualice constantemente.

Gráfico 1. Respuestas de los encuestados respecto a diferentes servicios del Portal de la red de bibliotecas de Castilla-la Mancha

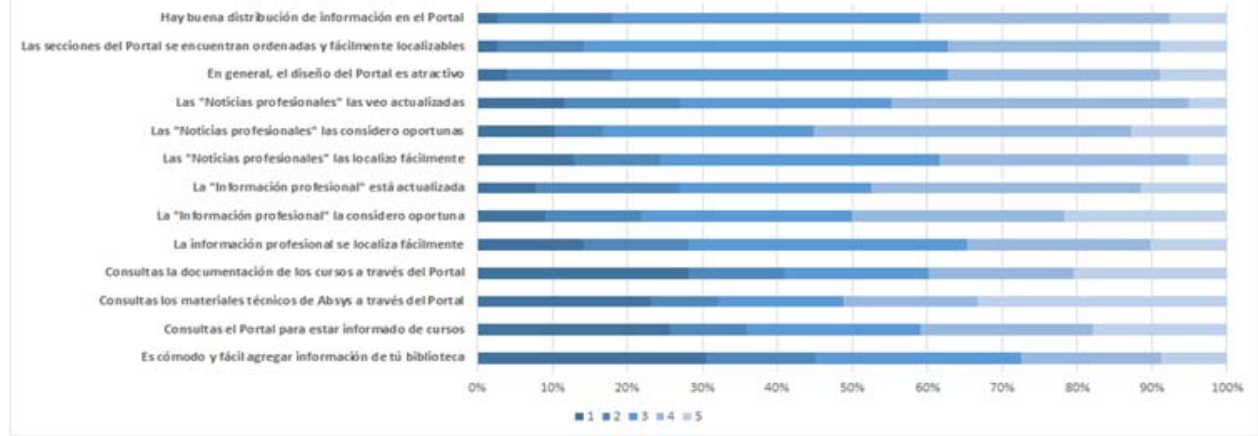

En el apartado de estudio relativo a la consulta de documentación de los cursos realizados a través de la Consejería de Educación, Cultura y Deportes y los 
materiales técnicos para la gestión técnica bibliotecaria a través del portal, existe más acuerdo sobre su consulta a través de este medio, (para la consulta de estos materiales no es necesario acceder con usuario y contraseña). Respecto a qué otro tipo de información querrían encontrar en el Portal, en general se requiere más información considerada de tipo técnico, como la inclusión de un foro dinámico de intercambio de ideas, la visualización de actividades de otras comunidades, así como las tendencias en el extranjero, el funcionamiento de bibliotecas pequeñas, o bien la formación de personal. El resto alude a que no conoce o visita el portal o que ya contiene la información necesaria.

Asimismo, en el portal existen dos apartados relacionados con los profesionales, "información profesional" y "noticias profesionales". Los encuestados describen que localizan con cierta facilidad este tipo de información. Sobre la oportunidad de la inclusión de este tipo de información, se observa disparidad de criterios, aunque ningún encuestado ha señalado que se trata del mismo tipo de información, lo que constata desconocimiento o bien una muestra del acceso fragmentado al portal.

En lo que respecta a la actualización, se comparte la misma opinión en las dos secciones, observando que en todas las cuestiones planteadas, los encuestados valoran más la información profesional. Ello quizá sea debido al tipo de epígrafe "información" sobre "noticias". Sobre las mejoras posibles en estas secciones, se encuentran respuestas aludiendo a que la encuentran bien tal y como está. Otras respuestas, sin embargo, se quejan de distintos aspectos relativos a los contenidos: a) la falta de actualización, b) la posibilidad de realizar mejoras en cuanto a su difusión, c) la posibilidad de incluir más documentación de los cursos impartidos, d) más facilidad de acceso, e) más información para bibliotecas de municipios pequeños, f) la ampliación del tamaño de la fuente (tipografía), g) la inclusión de índices por temas y bibliotecas, h) noticias de otras comunidades, i) mejor accesibilidad, y otros comentarios menores relativas a cuestiones técnicas y de difusión.

\subsubsection{El portal y tus usuarios}

En este apartado se pretende recabar información sobre la relación entre la ciudadanía, los bibliotecarios y el uso y promoción del portal como fuente de información. Por ejemplo, la posibilidad de orientar sobre las acciones que se pueden realizar a través del portal habría de realizarse a través de los Servicios Centrales, pero por la proximidad y la atención individualizada en ciertos aspectos como puede ser la consulta de uso de eBiblio o del OPAC, la figura del bibliotecario puede ser muy valiosa y necesaria. Por ello, un buen conocimiento de sus recursos es indispensable por parte de los bibliotecarios. También se tendría que tener en cuenta la opinión directa de los usuarios como hicieron Geetha, Mamatha y Farhana (2013) en el portal de la biblioteca universitaria de Kuvempu, donde examinaron factores como la actividad y perfección, propósito, uso y beneficios de su utilización, con el objeto de identificar las dificultades de los encuestados en el uso del portal. 
La mayoría de los bibliotecarios fomentan adecuadamente el uso del portal y del OPAC, y las renovaciones de forma presencial. Sin embargo, los que no lo promueven lo atribuyen bien a la preferencia de los usuarios en acercarse a la biblioteca para este tipo de acciones, bien por desconocimiento, o incluso una respuesta alega que la información que recoge no parece de interés para sus usuarios.

Gráfico 2. Promoción del portal. Fuente (elaboración propia)

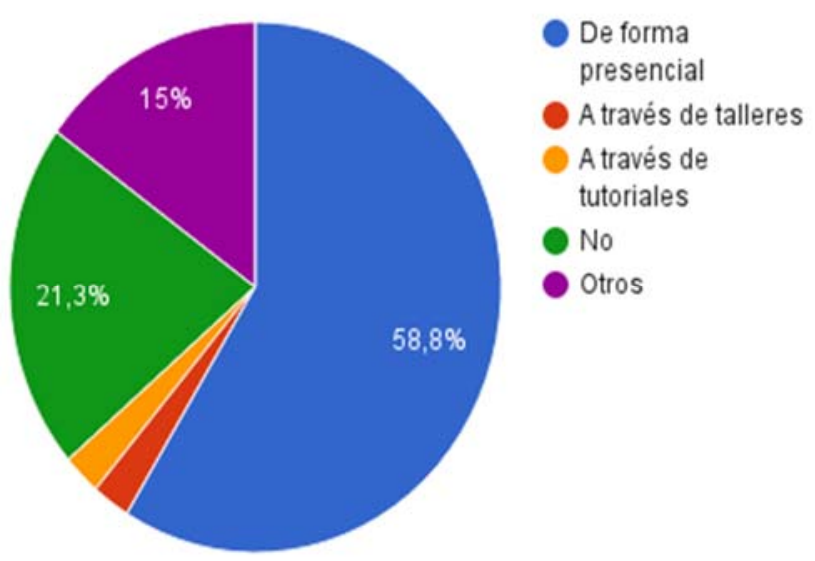

Valorando del 1 (en desacuerdo) al 5 (totalmente de acuerdo) el diseño del portal, el orden de las secciones y la distribución de la información, se obtienen los resultados del gráfico 3. La mayoría de las respuestas sobre la utilidad del portal son afirmativas (ver gráfico 3), destacando que se alude a la falta de promoción desde la propia Consejería. En otro sentido, algunas respuestas lo ven únicamente como herramienta de información y como tablón de información imprescindible. Sobre los aspectos que deberían cambiarse, se alude a: a) el diseño, b) las actualizaciones, debiendo ser más frecuentes c) mayor dinamismo, ordenación y distribución de los contenidos d) mayor facilidad de acceso, e) más eficacia en las tramitaciones e información más extensa f) mayor publicidad y visibilidad, g) que se favorezca la conexión entre profesionales y la interactividad de cara al usuario, h) renovar la imagen, con más sencillez de uso i) incluir una lista de distribución para los profesionales y finalmente, $\mathrm{j}$ ) darle mayor importancia. 
Gráfico 3. Distribución, diseño y localización. Fuente (elaboración propia)

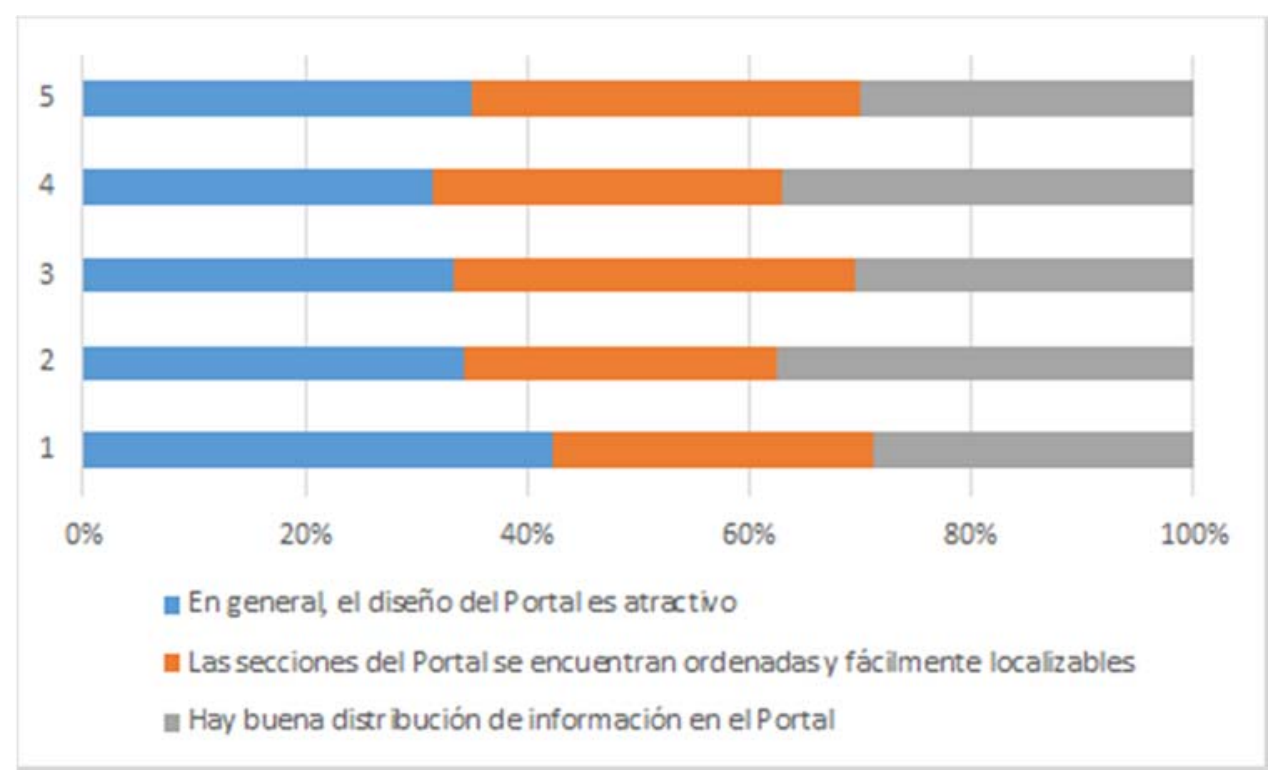

\section{Discusión y recomendaciones}

El desarrollo y la implementación de servicios de información implica tenerlos actualizados, comprobar que están en sintonía con las necesidades y las expectativas de los usuarios a los que van dirigidos, así como mantener una política clara y estable en cuanto a incorporación de contenidos. Maniega-Legarda, PérezSalmerón y Guerrero-Torres (2008) concluyen que "la clave es pensar como usuarios, aportando los conocimientos profesionales para organizar la información de la mejor manera sin tejer redes complejas". Por su parte, Castillo-Díaz y Jiménez-Fernández (2010) recomiendan que "a los usuarios se les facilite información de valor, debidamente estructurada y adaptada a sus intereses particulares". Para conseguir todo ello, el PBPCM debería tener en consideración los siguientes aspectos, entre ellos:

Actualizar con más asiduidad e indicar fecha de publicación de los contenidos. Se ha señalado que en algunos casos como en "los más prestados de la Red", no consta ni de fecha de publicación ni de actualización, no indicando de esta forma al usuario a qué periodo se refieren. Así mientras que las listas de los libros más prestados elaboradas por editoriales o medios de comunicación se actualizan mensualmente, ¿por qué no las bibliotecas? La inmediatez es una de las características de este tipo de información.

En la Tabla 13 se presentan las principales y recomendaciones respecto a la evaluación. 
Tabla 13. Resumen. Fuente (elaboración propia)

\begin{tabular}{|l|l|}
\hline \multicolumn{1}{|c|}{ PARÁMETRO } & \multicolumn{1}{c|}{ OBSERVACIONES } \\
\hline Autoría/Contenido & - Evitar enlaces redundantes \\
& - Incluir fecha de actualización \\
\hline Navegación/Recuperación & - Reducir opciones en el menú de la derecha \\
& - Insertar trazas de navegación \\
& - Incluir índices \\
\hline Ergonomía/Legibilidad & - Restimizar sistema de etiquetas \\
\hline Luminosidad & - Agrupar los enlaces por categorías \\
& - Resolver la redundancia en la anticipación \\
\hline
\end{tabular}

El portal cuenta con un buen sumario en la parte superior, que adelanta al usuario los contenidos a los que podrá acceder. Sin embargo, no todos ellos se encuentran en ese menú. Así, en la parte derecha existen demasiadas opciones no incorporadas al sumario principal. Racionalizando y reestructurando éste menú se podría conseguir una página más organizada y ligera, descargando de enlaces e iconos la página principal, evitando la duplicidad de contenidos.

Por otra parte, la uniformidad en todo el portal añadiría valor al conjunto, si todas las secciones y todas las acciones estuvieran indicadas con la misma puntualidad. Se ha comprobado que la orientación no es uniforme en todas ellas. En este sentido, el usuario agradecería saber dónde está en cada momento. Asimismo, la anticipación sobre a dónde se va a dirigir mejoraría si en el texto de anclaje no repitiera información. También cabría señalar que al ir incorporando secciones, un buen sistema de índice ayudaría. En este sentido la afirmación de Codina (2008) diferenciando entre sumario e índice, según la cual "el primero es una representación abstracta y sistemática de la estructura del contenido de la web, mientras que los índices son listas detalladas no sistemáticas de los ítems temáticos, temporales, etc. de la web". Patsoule y Koutsabasis (2014), por su parte, indican que "el rediseño de sitios web es una tarea compleja que requiere el uso de métodos organizados y directrices, así como de evaluaciones significativas".

En cuanto a comodidad y facilidad de utilización del recurso, el único aspecto a mejorar sería la posibilidad de poder aumentar el tamaño de letra para alcanzar una óptima facilidad de lectura a la ciudadanía que así lo requiera. Aunque existe la opción, se ha verificado que no es ejecutable. También se debería revisar la duplicidad de información. En nuestro estudio hemos encontrado distintas secciones con el mismo contenido, cosa que conlleva que, además de una sobrecarga del portal, una posible desorientación del usuario. Sin duda, la revisión periódica de contenidos evitaría este tipo de errores. 
Aunque en páginas culturales la adaptación no es frecuente, para conseguir un óptimo grado de ergonomía, la flexibilidad y legibilidad, los contenidos deberían ser adaptables a las necesidades de cada usuario. En cuanto al acceso a profesionales, en la presentación del portal, ya se aludía a la demanda por parte de los bibliotecarios de Castilla-La Mancha de disponer de un espacio propio en el que dar cabida a contenido de carácter más técnico, incluyendo sección de noticias, blog, grupos de trabajo.

Bringula (2011) investigó los factores que podrían afectar significativamente a la usabilidad del portal web de la Universidad de East-Manila, mediante cuestionarios a 82 miembros de la facultad, mostrando que existe por parte de los bibliotecarios una cultura de compartir información para mejorar el servicio y dar visibilidad a los productos y a las acciones desarrolladas. Al confeccionar la encuesta, no se hicieron preguntas sobre la importancia de la gestión del conocimiento, ni sobre si veían el portal como un repositorio de información profesional, sino que se realizaron preguntas más genéricas para no influir en este aspecto. Así, las respuestas por sí mismas son recomendaciones de primera mano, y se ha visto que los profesionales solicitan más difusión del portal y más reciclaje en cuanto a su uso y potencial, tanto para los profesionales como para los usuarios, ya que consideran que no hay información suficiente sobre su existencia y uso.

Finalmente, el tipo de información profesional que también les gustaría encontrar en el portal sería: a) información de otras bibliotecas de la Red (en este aspecto, se alude mucho a que se da poca voz a actividades realizadas en bibliotecas de localidades pequeñas), b) tendencias en el extranjero, c) actividades de otras bibliotecas, d) formación de personal, e) información más actualizada sobre los cursos que oferta anualmente la Consejería para los profesionales de la Región, f) mayor frecuencia de actualización de la información, g) existencia de un foro ágil para la comunicación entre los profesionales, h) más actualidad técnica, i) alfabetización informacional, j) situación actual de la profesión bibliotecaria, así como encuentros profesionales y experiencias profesionales.

\section{Conclusiones y futuras líneas de investigación}

De los resultados obtenidos mediante las dos metodologías desarrolladas, podemos extraer las siguientes conclusiones. La formación de los bibliotecarios sobre el acceso y uso del Portal permitiría sin duda la mejora de la vinculación y difusión de los centros, a la vez que dotarlo de repositorios de información que ayuden a los profesionales en las tareas y actividades diarias. Ello facilitaría poder hacer del portal un foro de intercambio de experiencias que proporcionase un banco de datos y una herramienta de trabajo que aportara finalmente valor añadido a la labor de las bibliotecas.

Con respecto al acceso e información, señalan los encuestados que la Consejería debería darle más promoción por otros cauces con el fin de que la información llegue a la mayoría de los usuarios potenciales, al ser considerado como un tablón de información imprescindible, así como una buena herramienta de información. 
Los aspectos que se podrían mejorar sería por una parte tener mayor visibilidad y por otro potenciar un índice por temas y por bibliotecas, así como una mayor actualización. Ello permitiría, en definitiva, hacerlo más atractivo para los usuarios a la vez que mejorar los servicios prestados. Respecto a la accesibilidad y usabilidad, se requiere una ampliación de los tamaños de letra. Finalmente, respecto al acceso, volvemos a incidir en la necesidad de revisar la reorganización de contenidos y la reestructuración del menú principal, ofreciendo así un esquema orientativo y jerarquizado sobre los contenidos y los servicios que ofrece el portal.

Respecto al futuro, sería interesante contar con la opinión de los ciudadanos/usuarios del PBPCM, a través de encuesta o formularios sobre aspectos para así conocer directamente su opinión respecto la facilidad de uso, un posible mejor diseño, la accesibilidad, la presentación de la información, etc., con el objeto de trabajar de forma continua en la mejora de los servicios. Conocer qué necesidades tienen los propios usuarios permitiría sin duda ofrecer servicios de aún mejor calidad, en sintonía con sus necesidades, a la vez que se pueda incrementar el rendimiento y valor de los servicios que ya se prestan.

\section{Referencias bibliográficas}

Ayuso García, M.D.; Martínez Navarro, V. (2006). Evaluación de calidad de fuentes de información y recursos digitales: guía de buenas prácticas. Anales de documentación, $\mathrm{n}^{\circ} .9,17-42$.

Battles, J. J. (2010) Designing and Building a Collaborative Library Intranet for All. Journal of Web Librarianship, 4 (2-3), 251-263.

Bringula, R.P; Basa, R. S. (2011) Factors Affecting Faculty Web Portal Usability. Journal of Educational Technology \& Society. 14 (4).

Calvo-Flores, J.-C.; Cano-Vers, M.; Permanyer-Bastardas, J. (2010). Red de Bibliotecas Municipales de la provincia de Barcelona. El profesional de la información, septiembreoctubre, 19 (5), 492-497.

Castillo-Díaz, A.; Jiménez-Fernández, C. M.. (2010). Comunicación corporativa de organizaciones que ofrecen recursos bibliotecarios en la Web. El profesional de la información, marzo-abril, 19 (2), 184-188.

Codina, L. (2000). Evaluación de recursos digitales en línea: conceptos, indicadores y métodos. Revista española de documentación científica, 23 (1), 9-44.

Codina, L. (2008). Metodología de análisis y evaluación de recursos digitales en línea (v. 7). Segunda parte. Barcelona: UPF. Sección de Ciencias de la Documentación, Obtenido de http://www.lluiscodina.com/wp-content/uploads/2014/04/indicadores 2008.pdf_[Consulta: 14 de noviembre de 2016]

Dee Ann, A. (2010) Information Portals: The Next Generation Catalog. Journal of Web Librarianship 4(4), 375-389.

Figuerola, C. G.; Alonso Berrocal, J. L.; Zazo, Á. F. (2013). Estructuras de colaboración entre las bibliotecas nacionales de la Comunidad Europea a través de sus portales web y de las redes sociales. Scire. 19 (2) jul.-dic. 33-44.

Geetha, M.; Mamatha, K. R.; Farhana, F. (2013). Use of Library Portal by Research scholars and faculty members of Kuvempu University: A survey. DESIDOC Journal of Library and Information Technology. 33(6), 509-515

Gómez Lendínez A.; Toboso Vicente, A. (2013) Un portal web adaptado a cada tipo de usuario: servicios digitales de la Red de Bibliotecas Municipales de la provincia de 
Barcelona En: VI Congreso Nacional de Bibliotecas Públicas [Recurso electrónico]: memoria individual, patrimonio global. Madrid: Subdirección General de Publicaciones, Información y Documentación, 327-341. http://ravesia.mcu.es/portalnb/ jspui/handle/10421/6708 [Consulta: 22 de noviembre de 2016]

Granic, A.; Mitrovic, I; Marangunic, N. (2011). Exploring the usability of web portals: A Croatian case study. International Journal of Information Management. 31(4), 339349. doi:10.1016/j.ijinfomgt.2010.11.001

Jeffery, K.; Dworak, E. (2010) Who Moved My Intranet? The Human Side of Introducing Collaborative Technologies to Library Staff. Journal of Web Librarianship, 4(2-3), 177-186.

Maniega-Legarda, D.; Pérez-Salmerón, G.; Guerrero-Torres, Y. (2008) El Portal de Biblioteques de la Generalitat de Catalunya: un proyecto para los ciudadanos y los profesionales de la biblioteca pública. El profesional de la información, marzo-abril, 17(2), 183-187.

Masrek, M.N.; Jamaludin, A.; Mukhtar, A. (2010). Evaluating academic library portal effectiveness: a Malaysian case study. Library Review, 59(3), 198-212

Merlo Vega, J. A. (2003) La evaluación de la calidad de la información web : aportaciones teóricas y experiencias prácticas. En: Felipe Zapico, A. (Coord.) Recursos informativos: creación, descripción y evaluación. Mérida: Junta de Extremadura. Obtenido de: http://gredos.usal.es/jspui/bitstream/10366/17956/1/DBD_Ev.\%20calidad\%20inf.\%20w eb.pdf [Consulta: 29 de marzo de 2016]

Packer, A. L. (2007) El sentido de los portales. El profesional de la información, mayojunio, 16(3), 177-180.

Patsoule, E; Koutsabasis, P. (2014). Redesigning websites for older adults: A case study. Behaviour and Information Technology. 33(6), 561-573.

Sarrafzadeh, M.; Martin, B.; Hazeri, A. (2010) Knowledge management and its potential applicability for libraries. Library Management, 31(3), 198-212.

Sellés, A.; Serrano-Cobos, J. (2011). Del OPAC extendido a la biblioteca expandida: al fin una realidad. El Profesional de la Información, jul-ago, 20(4), 460-464.

Soto, A.; Soescún, S. (2015) Servicios innovadores en las bibliotecas públicas de Colombia. Resultados de un estudio Delphi. El profesional de la información, 24(6), 778-786.

Tramullas, J. ( 2015) Gestión de contenidos, 2005-2015: una revisión. Hipertext.net [Online], Núm. 13. http://raco.cat/index.php/Hipertext/article/view/294025/3894

Vaughan, J. (2001). Three iterations of an academic library Web site. Information Technology and Libraries. 20(2), 81-92.

Villaseñor Palma, K.; Úcar, J. (2011) El Capital social en la biblioteca universitaria". Boletín de la Asociación andaluza de bibliotecarios. $\mathrm{n}^{\circ} .102$ Obtenido de: https://dialnet.unirioja.es/servlet/articulo? codigo $=4004273$

\section{Agradecimientos}

Para la elaboración de este artículo ha sido imprescindible, por lo cual doy las gracias al Servicio de Bibliotecas, Libro y Lectura de la Consejería de Educación, Cultura y Deportes de Castilla-La Mancha, en especial a Óscar Arroyo Ortega (Jefe de Servicio) por su ayuda, apoyo e interés mostrado en este estudio ofreciéndome toda la información disponible, y a Flor García Agüera (Jefe de la Sección de Coordinación Bibliotecaria) por la difusión de la encuesta, por su colaboración a todos los compañeros que de forma desinteresada han realizado la encuesta. 